\title{
The Effect of Rotating Magnetic Field on Enterotoxin Genes Expression in Staphylococcus Aureus Strains
}

\author{
Karol Fijałkowski ${ }^{1 *}$, Dorota Peitler ${ }^{1}$, Anna Żywicka ${ }^{1}$, and Rafal Rakoczy ${ }^{2}$ \\ ${ }^{1}$ Department of Immunology, Microbiology and Physiological Chemistry, West Pomeranian University of Technology, Szczecin, Poland \\ ${ }^{2}$ Department of Chemical Engineering, West Pomeranian University of Technology, Szczecin, Poland
}

(Received 29 January 2016, Received in final form 7 March 2016, Accepted 8 March 2016)

\begin{abstract}
Staphylococcus aureus cultures exposed to rotating magnetic field (RMF) were studied in order to analyse the possible induced changes in staphylococcal enterotoxin genes (se) expression. Liquid cultures of $S$. aureus strains carrying different se were exposed to the RMF of magnetic frequency $50 \mathrm{~Hz}$ and magnetic induction 34 $\mathrm{mT}$ for $10 \mathrm{~h}$ at $37^{\circ} \mathrm{C}$. Three time points of bacterial growth cycle were considered for RNA extractions. Gene expression analyses were evaluated using real-time quantitative PCR method. The present study confirmed, that the RMF can stimulate the growth rate of $S$. aureus cultures in comparison to the unexposed controls, while the stimulation is not strain dependent. The studies have also shown, that the RMF, depending on the exposure time but regardless the bacterial strain, can influence on the expression of various se. In general, except for sea, as a result of bacterial exposure to the RMF through subsequent growth phases, the expression of se decreased, reaching the values below results recorded for unexposed controls. In the case of sea expression remained at a lower level as compared to the control, regardless the time of exposition.
\end{abstract}

Keywords : rotating magnetic field, Staphylococcus aureus, gene expression, enterotoxin, real-time PCR

\section{Introduction}

Magnetic fields (MFs) can induce a variety of effects in cells and tissues. Among these effects are altered transcription of hsp 70 stress gene [1] and the immediate early response of myc, jun and fos genes [2,3]. The increased expression of stress genes in the presence of the MFs suggest that cell respond to the MFs as an environmental stress. It is assumed that the MFs interact initially with the cell membrane, activating signal transduction pathways that lead to the nucleus and result in stress protein synthesis [4]. It was also shown that various types of the MFs can influence on functional processes in microorganisms, including their pathogenicity potential $[5,6]$. Similarly, to eukaryotic cells, also bacteria (e.g. Escherichia coli) responded to the MF exposure with enhanced expression of the stress proteins [7].

Food-borne diseases are of major concern worldwide. Among the predominant bacteria involved in these diseases, staphylococci (especially Staphylococcus aureus)

CThe Korean Magnetics Society. All rights reserved.

*Corresponding author: Tel: +48-91-449-6714

Fax:+48-91-454-1642, e-mail: karol.fijalkowski@zut.edu.pl are a principal cause of gastroenteritis resulting from the consumption of contaminated food [8] Staphylococcal food poisoning (SFP) is an intoxication that results from the consumption of foods containing sufficient amounts of one (or more) preformed enterotoxin (SE). The classical types of SEs have been recognized as SEA, SEB, SEC, SED, SEE $[8,9]$. SEs produced by $S$. aureus are resistant to inactivation by digestive tract enzymes as well as by heat. Data on the enterotoxigenicity of $S$. aureus isolated from human and food indicate that more than $50 \%$ of strains are enterotoxigenic [10]. It is well known that environmental factors effect on the expression of enterotoxins. However, this process is not fully understood. It is agreed upon, that improved understanding of how environmental factors affect the expression of enterotoxins would enable to develop new strategies for improved food safety [11].

The studies on the influence of the MFs on microorganisms performed to date, concern mainly the static magnetic fields (SMFs), whereas the research on the rotating magnetic fields (RMFs) are still relatively limited and the potential influences of the RMFs on the microorganisms remain unexplored in many aspects. The RMF is a MF which changes direction, ideally, at constant 
angular rate. The RMF arises as a resultant field during the superposition of two or more alternating-current magnetic fields of identical frequency but spatially displaced in phase with respect to one another. Therefore, the RMF changes over time and can be characterized by its frequency [12]. The RMF is most commonly used in electromechanical applications such as induction motors, electric generators and alternators [13]. Based on the review of patent literature, it was noted that the RMF can also be used in various apparatuses for food processing. Thus, it can be assumed, that the exposure to this kind of MF occurs repeatedly during the transformation of raw ingredients into the food. As examples, the following inventions can be mentioned: "Food processing apparatus including magnetic drive" [14], "Magnetic drive for food processing apparatus" [15] or "Apparatus for processing of foodstuffs with magnetic drive" [16]. Therefore, it can be assumed that the bacteria present (contaminated or naturally occurring) in the food during its processing using the magnetically assisted equipment may also be exposed to the RMF.

The aim of this study was to analyze the impact of the RMF on the genes encoding enterotoxins in $S$. aureus strains. We aimed to answer the following questions: (i) whether the exposure to the RMF can be used as an agent to alter enterotoxins production? (ii) whether the use of the RMF in food production may increase the risk of intoxication with staphylococcal enterotoxins?

\section{Experimental}

\subsection{Material and Methods}

In the experiment three reference strains of $S$. aureus with genes encoding various enterotoxins were used (Table 1). In order to analyze if the influence of the RMF on the level of enterotoxin gene expression can be strain dependent, two additional strains carrying $\sec$ gene were used. $S$. aureus without enterotoxin genes served as a negative control.

Initially, bacteria were plated onto Columbia Agar with $5 \%$ sheep blood (Grasso, Poland) and cultivated for $24 \mathrm{~h}$

Table 1. S. aureus reference strains used in this study.

\begin{tabular}{lll}
\hline \hline Strains & Enterotoxin genes & Reference \\
\hline FRI913 & sea, sec, see & {$[17]$} \\
Col & seb & {$[17]$} \\
N315 & sec & {$[18]$} \\
FRI137 & sec & {$[18]$} \\
FRI1151m & sed & {$[19]$} \\
$8325-4$ & no SAg genes (control) & {$[19]$} \\
\hline
\end{tabular}

at $37^{\circ} \mathrm{C}$. After the incubation, one colony forming unit (CFU) of each strain was transferred into $10 \mathrm{~mL}$ of Tryptic Soy Broth (TSB, Oxoid, UK) and incubated another $24 \mathrm{~h}$ at $28^{\circ} \mathrm{C}$ with shaking $(200 \mathrm{rpm})$. Cultures were diluted in TSB broth to obtain the same optical density (OD) equals $1 \times 10^{8} \mathrm{CFU} / \mathrm{mL}$. In the next step, 1 $\mathrm{mL}$ of the resulted bacterial suspension was transferred to inoculate $10 \mathrm{~mL}$ of TSB into $15 \mathrm{~mL}$ plastic tubes with caps featuring 8 holes and a specific capillary pore filter membrane with a pore size of $0.2 \mu \mathrm{m}$ providing gas exchange (CELLSTAR ${ }^{\circledR}$ CELLreactor $^{\mathrm{TM}}$, Polypropylene Filter Top Tube, Greiner Bio-One, USA) and cultivated under experimental conditions, described below.

The exposition of bacteria to the RMF was carried out using self-designed set-up, described in our previous work [20] and adopted for purposes of this research. This set-up is schematically presented in Fig. 1. The generator of the RMF was made of a three-phase stator of an induction squirrel cage motor and a glass container filled with water that was an incubator for the tubes with bacteria placed inside it during the exposition. The RMF was generated by coils located around the cylinder. When the alternating current supplied the windings, the generated magnetic field rotated around the cylinder axis with the constant angular frequency of RMF. The frequencies of the RMF were changed by the transistorized inverter (Commander SK, APATOR, Poland). The incubation temperature during the exposition to the RMF was cont-

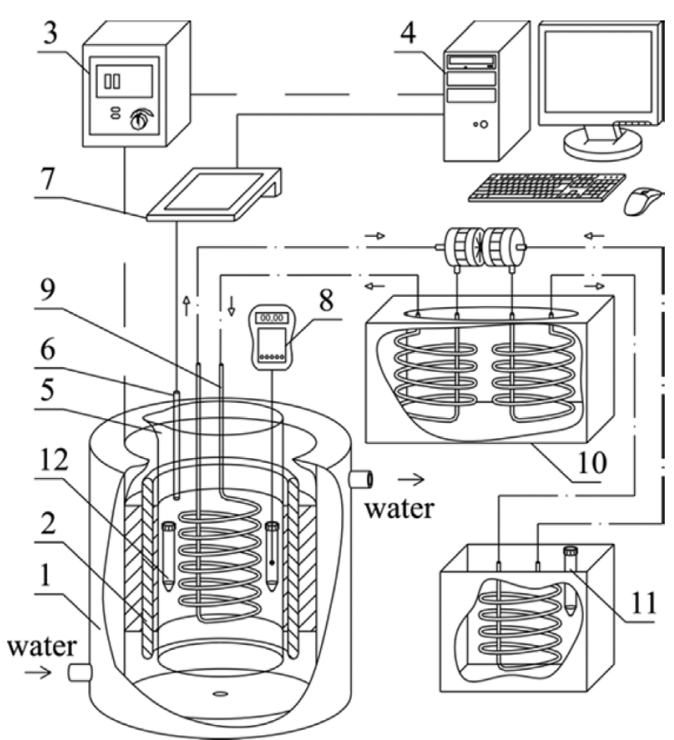

Fig. 1. Sketch of experimental set-up: 1 - cooling jacket, 2 RMF generator, 3 - ac transistorized inverter, 4 - personal computer, 5 - container, 6 - temperature sensor, 7 - multifunction computer meter, 8 - Hall magnetic sensor, 9 - internal coil, 10 - thermostat, 11 - control probe, 12 - test probe. 
rolled by the thermostat (UTU-3, ZEAMiL, Poland), the cooling jacket and the circulating pump (WZ-250/BY, Poland). The temperature fluctuation inside the glass container during the experiment was measured using the microprocessor temperature sensors (LM-61B, National Semiconductor Corporation, USA). The values of magnetic induction $(B)$ at the frequency $(f)$ of RMF equals $50 \mathrm{~Hz}$ were detected inside the single tube with inoculum using the Hall probe (Smart Magnetic Sensor-102, Asonik, Poland). The measurements were repeated several times and mean value of $B$ was calculated as equals to $34 \mathrm{mT}$ $( \pm 0.5 \mathrm{mT})$. The test tubes with microorganisms were placed in the center of the coil of the RMF generator where the MF is maximal.

The same bacterial strains, incubated in the same time and under the same conditions but without exposure to the RMF served as a control of the experiment. The controls were incubated in the water bath used to maintain the temperature of the test tubes in the RMF generator. The fluctuation of temperature was the same for tested and control samples, with deviation less than 0.5 ${ }^{\circ} \mathrm{C}$. It was confirmed using - Hall probe that the source of the RMF did not have an impact on the controls during the experiment $(B \leq 0.05 \mathrm{mT})$.

The growth rate of bacterial cells during the experiment was measured by optical density (OD) readings at the wavelength of $600 \mathrm{~nm}$ in 96 well plates with $200 \mu \mathrm{L}$ of each sample of bacterial cultures taken every hour between 1-10 $\mathrm{h}$ of exposure to RMF using Infinite 200 PRO NanoQuant microplate reader (Tecan, Männedorf, Switzerland).

Samples for RNA extraction were taken at three different times during an in vitro growth: in the midexponential growth phase $(3 \mathrm{~h}$ after the start of experiment), late-exponential phase $(3 \mathrm{~h}$ after the first time point), and early stationary growth phase ( $3 \mathrm{~h}$ after the second time point). Cells were collected by centrifugation for $10 \mathrm{~min}$ at $4{ }^{\circ} \mathrm{C}$ at $4,000 \times \mathrm{g}$. The resulted cell pellets were washed in PBS, centrifuged at $4,000 \times \mathrm{g}$ for $10 \mathrm{~min}$, supplemented with $0.5 \mathrm{~mL}$ of RNA later (Ambion, USA) and frozen at $-20{ }^{\circ} \mathrm{C}$ to prevent RNA degradation. The RNA extraction was prepared using Total RNA Mini kit protocol (A\&A Biotechnology, Poland) according to the manufacturer's instructions. The extracted RNA was treated using RNase-free DNase I (Invitrogen, USA) to eliminate residual genomic DNA. The final RNA concentration was determined using Quant-iT ${ }^{\mathrm{TM}}$ RNA Assay Kit (Invitrogen, USA), the purity was assessed spectrophotometrically (by the A260 nm/A230 nm and A260 $\mathrm{nm} / \mathrm{A} 280 \mathrm{~nm}$ ratios) using Biophotometer (Eppendorf, Hamburg, Germany) and integrity of the RNA samples was evaluated by agarose gel electrophoresis. Two independent cultures and RNA extractions were performed for each strain. The reverse transcription of $100 \mathrm{ng}$ of total RNA was performed using commercial kit (Tran Scribe Kit, A\&A Biotechnology, Poland) according to the manufacturer's instructions. The cDNA samples were quantified by measuring A260 nm/A280 nm ratio using a Biophotometer.

The real-time quantitative PCR (RT-qPCR) analysis were performed using an Eco Real-Time PCR System (Illumina, USA). The primers for enterotoxin genes and housekeeping genes (HKG) of $S$. aureus are shown in Table 2. All reactions were conducted in $12.5 \mu \mathrm{L}$ of

Table 2. Primer sequences for real-time quantitative PCR analysis.

\begin{tabular}{|c|c|c|c|}
\hline Gene & Primer & Nucleotides sequence & References \\
\hline \multirow[t]{2}{*}{ gyrB } & GYR 1 & 5' CCAGGTAAATTAGCCGATTGC 3' & [21] \\
\hline & GYR2 & 5' CTCTGMACCTTYCCATCAAA 3' & \\
\hline \multirow[t]{2}{*}{ pta } & PTA1 & 5' AAAGCGCCAGGTGCTAAATTAC 3' & {$[21]$} \\
\hline & PTA2 & 5' CTGGACCAACTGCATCATATCC 3' & \\
\hline \multirow[t]{2}{*}{$f t s Z$} & FTSZ1 & 5' ATCCAAATCGGTGAAAAATTAACAC 3' & [21] \\
\hline & FTSZ2 & 5' CCATGTCTGCACCTTGGATTG 3' & \\
\hline \multirow[t]{2}{*}{ sea } & SEA1 & 5' CCTTTGGAAACGGTTAAAAC 3' & {$[22]$} \\
\hline & SEA2 & 5' AAAGATTTGCGAAAAAAGTCTGAATT 3' & \\
\hline \multirow[t]{2}{*}{ seb } & SEB1 & 5' GGGTATTTGAAGATGGTAAAAATT 3’' & {$[22]$} \\
\hline & SEB2 & 5' AGGCGAGTTGTTAAATTCATAGAGTT 3' & \\
\hline \multirow[t]{2}{*}{$\sec$} & SEC1 & 5' TGTACTTRTAAGAGTTTATGAAAATA 3' & {$[22]$} \\
\hline & SEC2 & 5' TCCTAGCTTTTATGTCTAGTTCTTGAG 3' & \\
\hline \multirow[t]{2}{*}{ sed } & SED1 & 5' AAACGTTAAAGCCAATGAAAACA 3' & {$[22]$} \\
\hline & SED2 & 5' TGATCTCCTGTACTTTTATTTTCTCCTA 3' & \\
\hline \multirow[t]{2}{*}{ see } & SEE1 & 5' CCTATAGATAAAGTTAAAACAAGC 3' & {$[22]$} \\
\hline & SEE2 & 5'ACCGCCAAAGCTGTCTGAG 3' & \\
\hline
\end{tabular}


reaction volume containing $2 \mu \mathrm{L}$ of the relevant cDNA, $0.38 \mu \mathrm{L}$ of each gene-specific primers, $(20 \mu \mathrm{M}), 1 \mu \mathrm{L}$ of dNTP $(100 \mu \mathrm{M}), 0.13 \mu \mathrm{L}$ of UNG, $1.25 \mu \mathrm{L}$ of buffer with SYBR Green, $5.76 \mu \mathrm{L}$ of water, $1.5 \mu \mathrm{L}$ of $\mathrm{MgCl}_{2}(25$ $\mathrm{mM})$ and $0.1 \mu \mathrm{L}$ of AmpliTaq Gold DNA polymerase (SYBR ${ }^{\circledR}$ Green PCR Core Reagents, Applied Biosystems, USA). The thermocycling program consisted of UNG incubation cycle for $2 \mathrm{~min}$ in $50^{\circ} \mathrm{C}$, polymerase activation for $10 \mathrm{~min}$ at $95{ }^{\circ} \mathrm{C}$, followed by 40 cycles of $95{ }^{\circ} \mathrm{C}$ for $0.15 \mathrm{~min}$ and $60{ }^{\circ} \mathrm{C}$ for $1 \mathrm{~min}$. Fluorescence readings were taken after each extension step, which was followed by a melting curve analysis $\left(0.15 \mathrm{~min}\right.$ in $95^{\circ} \mathrm{C}, 0.15 \mathrm{~min}$ in $55{ }^{\circ} \mathrm{C}$ and $0.15 \mathrm{~min}$ in $95{ }^{\circ} \mathrm{C}$ ) based on continuous fluorescence readings. All real-time PCR analysis were performed twice. A blank (no-template control) was included in each assay.

The threshold cycle values $\left(\mathrm{C}_{t}\right)$ for each transcript calculated by the Eco Real-Time PCR System software were used for the relative quantification analysis. To normalized data, three HKGs, including gyrB, ftsZ, pta (Table 2) were quantified on the same batch of cDNA and the real-time PCR run as the genes of interest. The HKGs used for normalization were chosen on the basis of published literature [21, 22]. The efficiency of the HKG was analyzed by using standard curve and linear regression. The standard curve was generated using serial 5fold dilutions of a pool of cDNA from the two different samples. Descriptive statistic of the derived $C_{t}$ values, including geometric mean (GM), arithmetic mean (AM), minimal (Min) and maximal (Max) value, standard deviation (SD), coefficient of variance (CV) and correlation between housekeeping genes (R) was computed using BestKeeper software to determine the stability of each HKG [23].

Enterotoxin genes expression was analyzed using delta$\mathrm{C}_{\mathrm{t}}$ relative quantification model. Results were shown relative to a calibrator sample (unexposed control) for which normalized relative expression ratio for each enterotoxin gene equals 1 . Normalization was applied by dividing the relative quantities of genes of interest by the geometric mean of the relative quantities of references genes [24].

\section{Results and Discussion}

Stress factors such as heat shock, UV irradiation or exposure to MFs can influence on transposition activity and expression of genes in various organisms. There are many data demonstrating direct and indirect influence of the MFs on the viability of bacterial cells [25], their morphological [5] and biochemical properties [7, 25], genetic variability and gene expression [7, 26]. Some literature data are already available according to which, the MF exposure may cause DNA damage in terms of point mutations [27] or degradation of DNA due to direct interaction or as a result of the activity of oxygen radicals [28]. The study concerning in vitro interactions between the MFs and DNA, revealed that the MFs exposure induces DNA alterations causing point mutations. Such mutations cause changes in DNA sequences and in consequence can lead to the disruption of various gene expression [27].

The present work is a continuation of our previous study [20] in which we investigated whether the RMF, depending on magnetic induction, frequency and time of exposure, can influence on the growth dynamics, cell metabolic activity and other biochemical processes in various microorganism, including $S$. aureus. In the current study, we investigated the effect of the RMF exposure on pathogenic potential of $S$. aureus strains expressed by the changes in activity of genes encoding staphylococcal enterotoxins. According to thorough review of the available literature, the research concerning the influence of the MFs, including the RMF on the expression of staphylococcal enterotoxin genes have not yet been performed.

RT-qPCR is the most sensitive and commonly used method for detection of genes expression [21]. Relative measurements of the changes in gene expression can be determined by using various internal HKGs. Ideally, the HKGs used in relative RT-qPCR studies are controls equally expressed under different conditions. Several HKGs have already been reported in $S$. aureus gene expression studies, including ftsZ [29], pta [30], $h u$ [31], and $g y r B$ [32]. However, previous studies have shown that the expression of the particular HKGs can be differentially regulated, depending on experimental conditions $[33,34]$. Therefore, the stability of the selected HGKs should be evaluated in the experimental conditions before the genes can be used for normalization procedure. For

Table 3. Descriptive statistics of housekeeping genes.

\begin{tabular}{llll}
\hline \hline Statistics & gyrB & fts & pta \\
\hline $\mathrm{GM}\left[\mathrm{C}_{\mathrm{t}}\right]$ & 30.34 & 30.36 & 30.54 \\
$\mathrm{AM}\left[\mathrm{C}_{\mathrm{t}}\right]$ & 30.35 & 30.37 & 30.54 \\
$\operatorname{Min}\left[\mathrm{C}_{\mathrm{t}}\right]$ & 29.32 & 29.57 & 29.98 \\
$\operatorname{Max}\left[\mathrm{C}_{\mathrm{t}}\right]$ & 31.49 & 30.81 & 31.05 \\
$\mathrm{SD}\left[ \pm \mathrm{C}_{\mathrm{t}}\right]$ & 0.53 & 0.35 & 0.37 \\
$\mathrm{CV}\left[\% \mathrm{C}_{\mathrm{t}}\right]$ & 1.75 & 1.16 & 1.22 \\
$\mathrm{R}[\mathrm{HKG}]$ & 0.79 & 0.61 & 0.91 \\
\hline
\end{tabular}

GM - geometric mean, AM - arithmetic mean, Min - minimal value, Max - maximal value, SD - standard deviation, CV - coefficient of variance and $\mathrm{R}$ - correlation between housekeeping genes. 
that reason, in the present study the stability of expression of the individual HKGs was evaluated (Table 3). The obtained results showed that ftsZ, pta and gyrB genes could be considered suitable for normalization of enterotoxin genes expression under the influence of the RMF. These three HKGs, were also recommended by Vandecasteele et al. [35]; Vandesompele et al. [24] and chosen as controls to normalize the enterotoxin genes data analysis in the experimental conditions (exposure to the RMF). Similarly, in the studies by Duquenne et al. [21] the genes ftsZ, pta and gyrB showed good expression stability in the experimental settings, during cultivation of $S$. aureus under different conditions of $\mathrm{pH}$, temperature and aeration and were chosen for normalization by these authors.

It is well known that the expression of enterotoxin genes is dependent on the bacterial growth phase, bacterial cell density and bacterial strain. Therefore, the current studies included different strains of $S$. aureus cultivated in TSB broth through various growth phases to reach different cell density in the culture. The growth was monitored by measuring OD of bacterial cultures during the cultivation and magnetic exposure (Fig. 2). Similar bacterial culture growth rate was observed for all strains. In agreement with our previous study, it was also confirmed that the RMF increased growth rate of exposed bacteria. Three time points of the bacterial growth cycle were considered for the total RNA extractions. The first sampling was

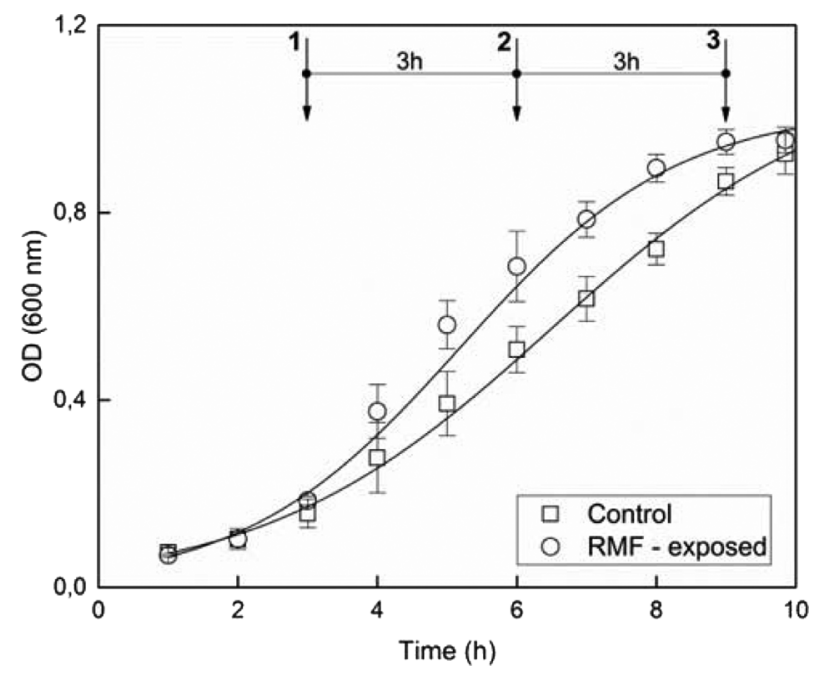

Fig. 2. Average growth of unexposed control and RMFexposed $S$. aureus strains. Liquid cultures of the bacteria were exposed to the RMF of $f=50 \mathrm{~Hz}(B=34 \mathrm{mT})$ during $10 \mathrm{~h}$ incubation at $37^{\circ} \mathrm{C}$. The growth rate was measured spectrophotometrically every hour at OD $600 \mathrm{~nm}$. Bars represent minimal and maximal values. performed in mid-exponential growth phase. The next samples were taken $3 \mathrm{~h}$ and $6 \mathrm{~h}$ later, in late-exponential and early stationary growth phases, respectively. The previous data on the relative mRNA abundance demonstrated that maximal enterotoxin $\mathrm{B}, \mathrm{C}$ and $\mathrm{D}$ production is achieved during the transition from the exponential to the stationary phases of growth, while SEA is produced throughout the exponential phase of growth [22]. It was also shown that except for SEA, the production of SEB, SEC, SED and SEE is regulated by the dependent upon the environment in which the organism is grown, accessory gene regulator (agr) system $[22,36]$. In the current study, the enterotoxin genes expression was analysed by RTqPCR with modified delta- $\mathrm{C}_{\mathrm{t}}$ relative quantification model, including PCR efficiency correction and multiple HKGs normalization [24]. The results are expressed as normalized quantities for each enterotoxin gene in the RMF exposed $S$. aureus strain relative to the unexposed control and presented in Fig. 3. Transcription of all enterotoxin genes were successfully detected in all strains and growth phases. The results demonstrated that exposure to the RMF resulted in changes in expression of all enterotoxin genes and $S$. aureus strains included in the experiment. In the mid-exponential microbial growth phase a visual increase in the expression of genes which activity is regulated by agr (seb, sec, sed and see) was observed. Among these genes, the highest expression in comparison to non-exposed controls, was recorded for the seb gene. However, it should be noticed, that despite of the increased expression of these genes, their activity in the exponential growth phase is reported as low [22] and should not be considered as significant in terms of bacterial pathogenicity. The further magnetic exposure to the late-exponential growth phases resulted in a reduction in the expression of these genes. However, the expression of sec (in two of the three strains) sed and see remained still on a higher level as compared to the unexposed controls. Then, as a result of continued exposure to the RMF through late-exponential and early stationary growth phases, the expression of these genes decreased below the results recorded for the unexposed controls. It was also found, that in contrast to $s e b, s e c$, sed and see, expression of the gene encoding enterotoxin A remained at a lower level in comparison to the non-exposed control gene, regardless the growth phase. The results obtained in the current study are partially reflected in the previous works on the factors affecting the changes in enterotoxin genes expression. As an example, it was showed that as a result of the modification in medium composition, the induction of the agr-regulated enterotoxin gene sec, was strongly impaired [37], while sea gene, which is not under the control of the 
(a)

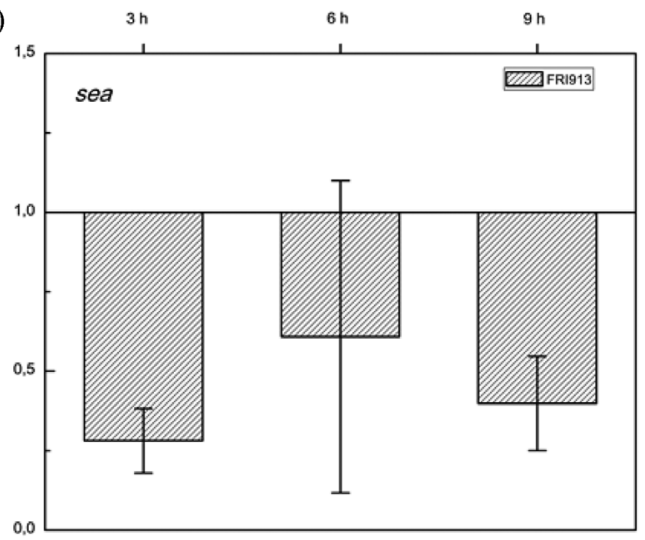

(c)

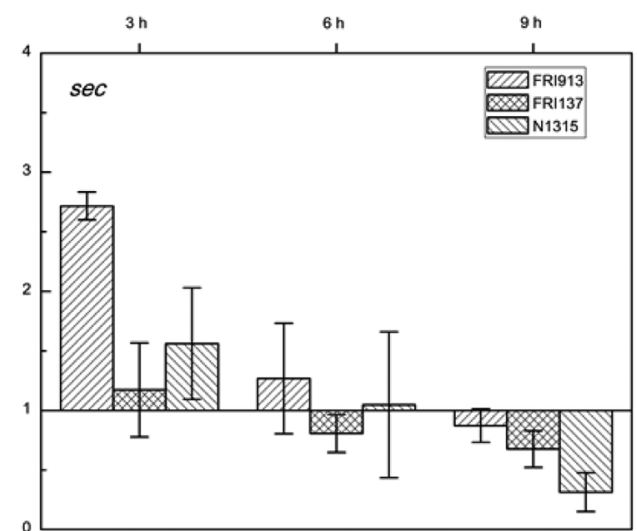

(e)

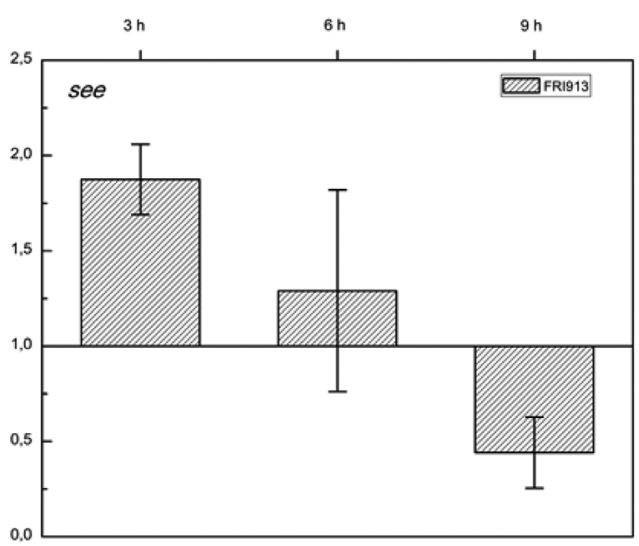

(b)

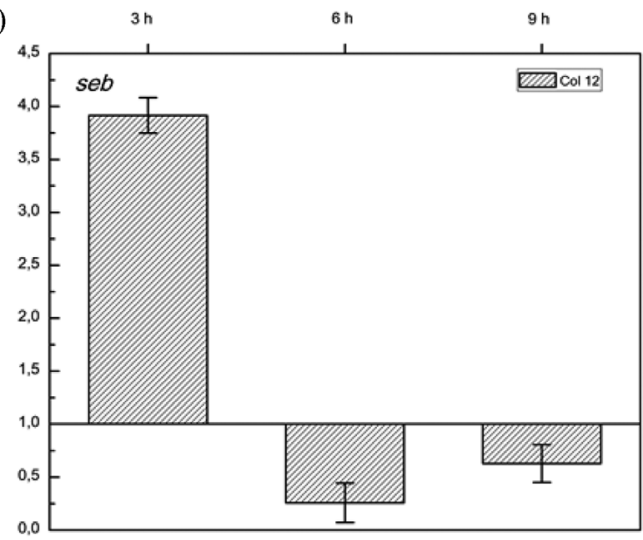

(d)

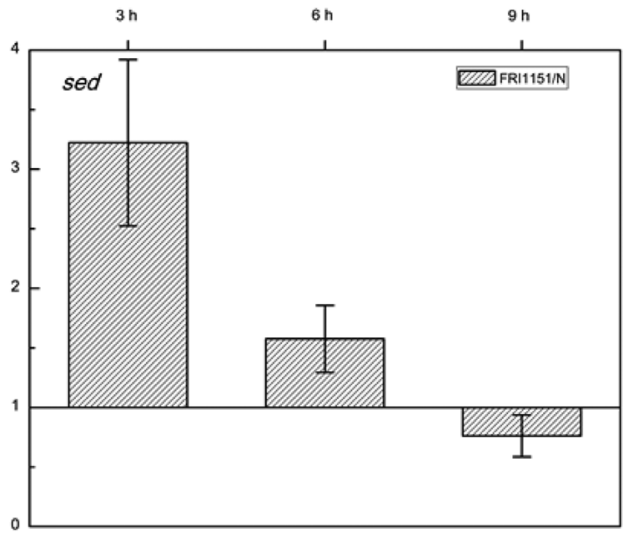

Fig. 3. Mean relative expression ratios for (a) sea, (b) seb, (c) sec, (d) sed and (e) see. Gene expression was quantified using RTqPCR. Normalization was performed using the geometric mean of 3 HKGs (ftsZ, pta and gyrB). Bacterial cultures were collected at 3 time points of growth: mid-exponential ( $3 \mathrm{~h}$ after the start of experiment), late-exponential ( $3 \mathrm{~h}$ after the first time point), and early stationary $(3 \mathrm{~h}$ after the second time point).

agr system did not change throughout the culture [38].

\section{Conclusions}

In summary, the present study confirmed that the RMF can stimulate the growth rate of $S$. aureus cultures, while the stimulation is not strain dependent. The MF-depen- dent bacterial growth stimulation can be considered an infectious agents and contribute to the development of food-borne diseases caused by staphylococci. On the other hand, the studies have shown that the RMF, depending on the exposure time, but regardless the bacterial strain, could decrease the expression of genes encoding various staphylococcal enterotoxins. It can therefore be 
concluded, that the application of the RMF in food processing devices does not affect or even reduce the risk of food poisoning, resulted from the ingestion of staphylococcal enterotoxins preformed in the food by enterotoxigenic strains of $S$. aureus.

\section{Acknowledgements}

We would like to thank dr Arkadiusz Terman from the Department of Genetics and Animal Breeding, West Pomeranian University of Technology in Szczecin for providing the equipment for real-time PCR analysis.

\section{References}

[1] H. Lin, M. Opler, M. Head, M. Blank, and R. Goodman, J. Cell. Biochem. 66, 482 (1997).

[2] J. L. Phillips, W. Haggren, W. J. Thomas, T. Ishida-Jones, and W. R. Adey, Biochem. Biophys. Acta. 1132, 140 (1992).

[3] H. Lin, M. Blank, M. Jin, and R. Goodman, Bioelectrochem. Bioenerg. 39, 215 (1996).

[4] R. Goodman and M. Blank, J. Cell. Physiol. 192, 16 (2002).

[5] L. Fojt, P. Klapetek, L. Strašák, and V. Vetterl, Micron. 40, 18 (2009).

[6] F. D. Matl, A. Obermeier, J. Zlotnyk, W. Friess, A. Stemberger, and R. Burgkart, Bioelectromagnetics 32, 367 (2011).

[7] L. Potenza, L. Ubaldi, R. De Sanctis, R. De Bellis, L. Cucchiarini, and M. Dachà, Mutat. Res. 561, 53 (2004).

[8] Y. Le Loir, F. Baron, and M. Gautier, Gent. Mol. Res. 2, 63 (2003).

[9] M. A. Argudín, M. C. Mendoza, and M. Rosario-Rodicio, Toxins (Basel) 2, 1751 (2010).

[10] M. E. Marín, M. C. de la Rosa, and I. Cornejo, Appl. Environ. Microbiol. 58, 1067 (1992).

[11] J. Schelin, N. Wallin-Carlquist, M. Thorup Cohn, R. Lindqvist, G. C. Barker, and P. Rådström, Virulence 2, 580 (2011).

[12] R. Rakoczy, Chem. Eng. Process. 66, 1 (2013).

[13] D. R. Patrick and S. W. Fardo, Rotating Electrical Machines and Power Systems (2nd ed.) Fairmont Press USA (1997) pp. 279-324.

[14] J. F. Jr Karkos, and R. Flanary, CA 2505561 A1 (2003).

[15] J. F. Jr Karkos, and R. Flanary, US 20100214867 A1 (2009).

[16] J. F. Jr Karkos, and R. Flanary, DE 60317091 D1 (2003).

[17] D. Wu, X. Li, Y. Yang, Y. Zheng, C. Wang, L. Deng, L. Liu, C. Li, Y. Shang, C. Zhao, S. Yu, and X. Shen, J. Med. Microbiol. 60, 35 (2011).

[18] M. Kuroda, T. Ohta, I. Uchiyama, T. Baba, H. Yuzawa, I. Kobayashi, L. Cui, A. Oguchi, K. Aoki, Y. Nagai, J. Lian, T. Ito, M. Kanamori, H. Matsumaru, A. Maruyama,
H. Murakami, A. Hosoyama, Y. Mizutani-Ui, N.K. Takahashi, T. Sawano, R. Inoue, C. Kaito, K. Sekimizu, H. Hirakawa, S. Kuhara, S. Goto, J. Yabuzaki, M. Kanehisa, A. Yamashita, K. Oshima, K. Furuya, C. Yoshino, T. Shiba, M. Hattori, N. Ogasawara, H. Hayashi, and K. Hiramatsu, Lancet. 21, 1225 (2001).

[19] S. Holtfreter, D. Grumann, M. Schmudde, N. T. Nguyen, P. Eichler, B. Strommenger, K. Kopron, J. Kolata, S. Giedrys-Kalemba, I. Steinmetz, W. Witte, and B. M. Bröker, J. Clin. Microbiol. 45, 2669 (2007).

[20] K. Fijałkowski, P. Nawrotek, M. Struk, M. Kordas, and R. Rakoczy, J. Magn. 18, 289 (2013).

[21] M. Duquenne, I. Fleurot, M. Aigle, C. Darrigo, E. Borezée-Durant, S. Derzelle, M. Bouix V. DeperroisLafarge, and A. Delacroix-Buchet, Appl. Environ. Microbiol. 76, 1367 (2010).

[22] S. Derzelle, F. Dilasser, M. Duquenne, and V. Deperrois, Food Microbiol. 26, 896 (2009).

[23] M. W. Pfaffl, A. Tichopad, C. Prgomet, and T. P. Neuvians, Biotechnol. Lett. 26, 509 (2004).

[24] J. Vandesompele, K. De Preter, F. Pattyn, B. Poppe, N. Van Roy, A. De Paepe, and F. Speleman, Genome Biol. 3, 34 (2002).

[25] J. Filipič, B. Kraigher, B. Tepuš, V. Kokol, and I. Mandic-Mulec, Bioresour. Technol. 120, 225 (2012).

[26] G. Giorgi, P. Marcantonio, F. Bersani, E. Gavoçi, and B. Del Re, Int. J. Radiat. Biol. 87, 601 (2011).

[27] L. Potenza, L. Cucchiarini, E. Piatti, U. Angelini, and M. Dachà, Bioelectromagnetics 25, 352 (2004).

[28] S. H. Li and K. C. Chow, Biochem. Biophys. Res. Commun. 280, 1385 (2001).

[29] W. R. Schwan, L. Lehmann, and J. McCormick, Infect. Immun. 74, 399 (2006).

[30] S. F. Pereira, A. O. Henriques, M. G. Pinho, H. De Lencastre, and A. Tomasz, J. Bacteriol. 189, 3525 (2007).

[31] Y. Chien, A. C. Manna, S. J. Projan, and A. L. Cheung, J. Biol. Chem. 274, 37169 (1999).

[32] C. Goerke, M. G. Bayer, and C. Wolz, Clin. Diagn. Lab. Immunol. 8, 279 (2001).

[33] O. Thellin, W. Zorzi, B. Lakaye, B. De Borman, B. Coumans, G. Hennen, T. Grisar, A. Igout, and E. Heinen, J. Biotechnol. 75, 291 (1999).

[34] K. Dheda, J. F. Huggett, S. A. Bustin, M. A. Johnson, G. Rook, and A. Zumla, Biotechniques 37, 118 (2004).

[35] S. J. Vandecasteele, W. E. Peetermans, R. Merckx, and J. Van Eldere, J. Bacteriol. 183, 7094 (2001).

[36] M. T. Tremaine, D. K. Brockman, and M. J. Betley, Infect. Immun. 61, 356 (1993).

[37] L. B. Regassa, J. L. Couch, and M. J. Betley, Infect. Immun. 59, 955 (1991).

[38] S. Even, C. Charlier, S. Nouaille, N. L. Ben Zakour, M. Cretenet, F. J. Cousin, M. Gautier, M. Cocaign-Bousquet, P. Loubiere, and Y. Le Loir, Appl. Environ. Microbiol. 75, 4459 (2009). 